\title{
Effect of breathing practices on visual and auditory reaction time of adolescent population in Madurai, India -A comparison of right and left nostril breathing
}

\author{
V. Suganthi ${ }^{1}$, S.Anu ${ }^{2, *}$, V. Mathava kumar ${ }^{3}$, K. Rekha ${ }^{4}$ \\ ${ }^{1}$ Associate Professor, ${ }^{2}$ Professor \& Head, ${ }^{3}$ Student, ${ }^{4}$ Assistant Professor, Dept. of Physiology, ${ }^{1}$ Vinayaka Mission \\ Kirupananda Variyar Medical College, Salem, ${ }^{\mathbf{2 , 3}, \mathbf{4}}$ Velammal Medical College, Madurai, India
}

*Corresponding Author:

Email: anu.sengottaiyan@gmail.com

\begin{abstract}
Introduction: Specific nostril breathing techniques are known to influence the autonomic function. Various studies have recorded that Right nostril breathing (RNB) exercises stimulate sympathetic activity and left nostril breathing (LNB) exercises stimulate parasympathetic activity. The present study was done to find out whether this is true by observing the immediate effect of specific nostril breathing on Visual Reaction Time (VRT) and Auditory Reaction Time (ART) of the same individual before and after training.

Aim and Objectives:

1. To assess the immediate effect of RNB \& LNB on VRT and ART.

2. To compare the immediate effect of RNB \&LNB on VRT \& ART.

3. To assess the Gender difference in the RNB \& LNB on VRT \& ART.

Materials and Methods: 40 MBBS students in the age group of 18-20 years were randomly selected. Group A $(n=20)$ consisted of male and Group B $(n=20)$ consisted of female volunteers. Subjects were taught breathing exercises on the first day and after 30 minutes of RNB, VRT \& ART and again after 30 minutes of LNB, VRT \& ART were recorded.

Results: A significant reduction in ART\& VRT and a significant increase in ART\& VRT were seen after RNB \& LNB exercises .No significant gender difference was observed on reaction time.

Conclusion: RNB stimulates sympathetic activity and LNB stimulates parasympathetic activity. ART is faster than VRT and no difference in reaction times between males and females were found after immediate breathing exercises.
\end{abstract}

Keywords: Autonomic function, Breathing exercises, Immediate, Reaction time.

Received: $7^{\text {th }}$ August, 2017

\section{Introduction}

The swiftness of the response to any stimuli depends on the speed of conduction of sensory nerves, motor nerves and the time taken for central processing. The time taken between application of a stimulus and the initiation of response is known as Reaction time. It serves as an index of sensory motor coordination. Audio visual (AV) reaction time plays an important role from the beginning to the end of the day. For example, the act of driving requires a faster AV reaction time, whereas a sound sleep requires a slow AV reaction time.

Specific nostril breathing techniques influence autonomic activity. At rest, in a normal individual uninostril dominance is seen, characterized by alternating patency of right and left nostrils in a 24 hour cycle. ${ }^{1}$ Alterations in nasal cycle periodicity have been linked to various diseases. It has been reported that regular practice of breathing exercises are known to alter autonomic function and that Right Nostril
Breathing (RNB) technique stimulates sympathetic activity by activating left cerebral hemisphere and Left Nostril Breathing (LNB) stimulates parasympathetic activity by

activating right cerebral hemisphere. ${ }^{2}$ A balancing effect on the left and right cerebral hemisphere was exhibited by Alternate nostril breathing. ${ }^{3}$ These evidences confirm that nasal airflow influences the brain activity depending on nostril dominance.

Studies have recorded that RNB increases Systolic, Diastolic and Mean arterial pressure whereas LNB decreases Systolic and Mean pressure. ${ }^{4}$ There is $37 \%$ increase in basal oxygen consumption after RNB and 24\% increase after LNB. Forced RNB increased blood glucose levels; whereas LNB decreased it. ${ }^{5}$ RNB produced a significant decrease in intraocular pressure by sympathetic stimulation. ${ }^{6}$ All these evidences suggest that RNB may have been expected to decrease Visual Reaction Time (VRT) \& Auditory Reaction Time (ART) by 
stimulating sympathetic activity and LNB to increase VRT \& ART by decreasing sympathetic and increasing parasympathetic activity.

It is a proven fact that males have a faster reaction time than females at rest. We want to elucidate in our study whether such differences in the reaction times between males and females existed after uninostril breathing exercises.

The direct and immediate effect of 30 minutes of specific nostril breathing practices, on the same individual on VRT \& ART is so far not documented. Hence, the present study was designed to assess the immediate effect right and left nostril breathing exercises on VRT \& ART.

\section{Aim \& Objectives}

1. To measure the immediate effect of Right Nostril Breathing on VRT \& ART.

2. To measure the immediate effect of Left Nostril Breathing on VRT \& ART

3. To compare the immediate effect of Right and Left Nostril Breathing on VRT \& ART of the same subject.

4. To assess the Gender difference in the Right and Left nostril breathing on VRT \& ART

\section{Materials and Methods}

The study was conducted in the Department of physiology, Velammal Medical College, Madurai on 40 Adolescent individuals of First Year MBBS students of both the genders in the age group of 18-20 years who were selected randomly after obtaining institutional ethical clearance. Informed consent was obtained from the volunteers after briefing about the study. Male subjects were assigned to Group A $(n=20)$ and female subjects $(n=20)$ to Group B randomly by using a randomization sequence generated in Microsoft Excel.

Healthy volunteers who had never practiced pranayama and who were almost on the same diet (medical college hostel students) were included in the study. Subjects with clinical evidence of any physical illnesses like diabetes, hypertension, and upper and lower respiratory diseases, subjects with ophthalmologic and hearing disorders, subjects suffering from any psychiatric disorder affecting their psychomotor abilities and subjects on autonomic modifying medication were excluded from the study.

\section{Description of intervention}

The volunteers were instructed to refrain from tea, coffee or any caffeinated drinks on the day of the study. Study was carried out regularly in the evening between $4-5 \mathrm{pm}$ to avoid the influence of circadian rhythm.

Baseline data on VRT\& ART was measured initially after familiarizing them with the technique. The participants were then taught specific nostril breathing exercises by a certified yoga instructor. These exercises were practiced with subjects in the sitting posture as posture influences reaction time. RNB involves alternate cycle on inhalation \& exhalation through the right nostril while the left nostril is occluded. There is no pause in between inhalation and exhalation and the subjects were asked to count 1-5 in their mind for each phase. The duration of one respiratory cycle is 10 seconds, so for 1 minute, there was 6 breathing cycles.

LNB involves alternate cycle on inhalation and exhalation through the left nostril while the right nostril was occluded. Once the skill was acquired, VRT \& ART values were measured after 30 minutes of RNB exercises on the first day. Likewise on the second day, for the same individual values were taken after 30 minutes of LNB.

\section{Data collection method \& tools}

Baseline \& end line data on all participants were collected using structured questionnaire. The study was carried out with the help of discriminatory and choice reaction time apparatus (Anand Agencies, Pune) and done on the same time of the day for all subjects to avoid influence of circadian rhythm. It had two modes of providing stimulus- auditory \& visual. VRT was measured for green and red light stimuli and ART was measured for low and high frequency sound stimuli. A distance of $80-100 \mathrm{~cm}$ should be there between the visual stimuli and the subject's eye. For recording the VRT, initially the subject was instructed to keep pressing the index finger on the response button and once he visualizes the stimulus, immediately he has to release his finger. The response button terminated the clock counter \& the value of VRT will be displayed on the screen in milliseconds. This process has to be repeated for 3 times, and the lowest value was then taken as the final reaction time. Baseline ART has also been recorded in the same way for both for tone \& click sound. Again after 30 minutes of RNB \& LNB exercises, VRT\& ART were recorded.

\section{Statistical Analysis}

The data was entered into MS excel and analysed using SPSS v16.0. VRT and ART values before and after nasal breathing were compared using paired $t$ test. Sex wise differences in the effect of nasal breathing on 
VRT and ART were analysed using unpaired $t$ test. An arbitrary cut off of 0.05 was used to interpret significance of $p$ value.

\section{Discussion}

In the present study, as shown in Table 1, VRT \& ART were significantly decreased $(<0.001)$ immediately after 30 minutes in the RNB group and increased $(<0.001)$ in the LNB group reconfirming the fact that RNB stimulates sympathetic activity and LNB stimulates parasympathetic activity. This result coincides with the previous study done on 20 subjects who had undergone yogic breathing exercise training for a period of 3 months where RNB showed effects mimicking sympathetic activity and LNB showed effects mimicking parasympathetic activity. ${ }^{7}$ The difference in reaction time is more for the RNB group than for the LNB group and this could be due to increased level of plasma catecholamines along with sympathetic stimulation. ${ }^{8}$

At rest nasal airflow is greater in one nostril than the other. ${ }^{1}$ Persistent blockage of one nostril could affect this rhythmic alteration in the nasal cycle and can lead to health issues due to imbalance of autonomic activity.

Normally left hemisphere is specialized for language functions and right hemisphere is specialized for spatio-temporal functions. In a study conducted on adult volunteers, right nostril dominant individuals scored better on verbal tasks and the left nostril dominant individuals scored better on spatial tasks. ${ }^{9}$ Uninostril breathing also showed increased EEG activity and Event related potential changes in the contralateral hemisphere. ${ }^{10,11}$ Heart Rate Variability indices representing sympathetic activity were increased in the RNB group and indices representing parasympathetic activity were increased in left nostril breathing group following 6 weeks of breathing training. ${ }^{12}$ All these evidences suggest that RNB technique stimulates sympathetic activity by activating left cerebral hemisphere and LNB technique increases parasympathetic by activating right cerebral hemisphere.

In the present study, subjects were asked to practice breathing exercises at a rate of only 6 breaths /minute, as regular practice of slow breathing exercises had shown significant changes in autonomic functions. Studies have proved that fast breathing exercises practiced for the same amount of time as slow breathing exercises had not altered the autonomic functions. ${ }^{2,13}$ Reaction time also changed significantly with changes in duration of voluntary breathing. ${ }^{14}$ In this study, even after 30 minutes of practice of specific nostril breathing exercises, significant changes were observed.

The mechanism by which these autonomic changes occur after breathing practices were so far clearly not documented and is still under debate. Suggested hypothesis could be that when cool air enters the nose during inspiration, trigeminal nerve gets stimulated..$^{15}$ This in turn activates brainstem reticular formation and increase arousal by stimulating wider areas of the cerebral cortex leading to changes in EEG and cognitive performance. Especially Cardiorespiratory centres in the brainstem which regulate the autonomic activity were influenced by breathing patterns. ${ }^{16}$

Reaction time to auditory stimulus was less when compared to visual stimulus before and after both the types of breathing which contradicts the results of a previous study where reaction time to visual stimulus was found to be lesser than auditory stimulus. ${ }^{17}$ But many studies have concluded that not only in sedentary but also in sports trained subjects ART was faster than VRT .Though it is proved that light travels faster than sound, this could be explained on the basis that an auditory stimulus takes only 8-10 $\mathrm{ms}$ to reach the brain while on the other hand ,a visual stimulus takes $20-40 \mathrm{~ms} .{ }^{18,19}$

In the LNB group there was no significant change in reaction time to green light after breathing exercises though an increase in the mean value had been observed (from 0.190 to $0.200 \mathrm{~ms}$ ). It is also shown in Table 2 that in both RNB \& LNB group the reaction time for the red light $(0.140 \mathrm{~ms}, 0.183 \mathrm{~ms})$ is faster than that of the green light $(0.154 \mathrm{~ms}, 0.200 \mathrm{~ms})$ and this coincides with the results of a study done on young volunteers. ${ }^{20}$ This could be explained on the basis of Trichromatic theory of colour vision which is based on three different pigments in the eye each absorbing a different range of wavelengths. ${ }^{21}$ The spectral sensitivity of photopic human vision is dominated in order by the longer wavelength red $(560 \mathrm{~nm})$ cone, then by green $(530 \mathrm{~nm})$ cone and then by the shorter wavelength blue cone which has one tenth absolute spectral sensitivity when compared with red and green. That means more number of red cones are stimulated than the other two.

There were mixed results regarding differences in reaction time between males and females. ${ }^{17,22}$ The present study showed no statistically significant gender difference on reaction time(Table 3) after breathing exercises though the reaction time mean value for most of the parameters(except for green light in LNB and tone in RNB) is faster in males. 
These results indicate that students can improve their performance in sports and academic activities by practicing RNB by increasing their alertness. But specific RNB exercises should not be practiced by hypertensive individuals with sympathetic over activity. Slow LNB techniques which could reduce blood pressure by increasing baroreflex sensitivity and decreasing sympathetic activity/chemoreflex activation should be advised. $^{23}$

\section{Limitation}

As nasal cycle alternates periodically, nasal dominance patterns of the subjects should have been considered before the intervention. For example, if the subject was found to be in right nostril dominant period before the intervention, he should be suggested to practice RNB technique that hour to get a better result.

\section{Results}

Table 1: Comparison of VRT and ART before and after nasal breathing- Left and Right

\begin{tabular}{|l|l|l|l|l|l|l|l|}
\hline $\begin{array}{l}\text { Nostril } \\
\text { breathing }\end{array}$ & & \multicolumn{2}{|c|}{ Before } & \multicolumn{2}{c|}{ After } & t test & $\begin{array}{l}\text { p- } \\
\text { value }\end{array}$ \\
\hline & & Mean & SD & Mean & SD & & \\
\hline \multirow{2}{*}{ Left } & VRT(ms) & .175 & .036 & .191 & .032 & -3.841 & $<0.001$ \\
\cline { 2 - 8 } & ART(ms) & .155 & .026 & .171 & .028 & -6.538 & $<0.001$ \\
\hline \multirow{2}{*}{ Right } & VRT(ms) & .170 & .026 & .146 & .024 & 9.284 & $<0.001$ \\
\cline { 2 - 8 } & ART(ms) & .156 & .017 & .137 & .023 & 7.232 & $<0.001$ \\
\hline
\end{tabular}

There was an increase in the mean VRT \&ART values $(0.191,0.171)$ after LNB from the baseline values and it was statistically significant $(\mathrm{p}<0.001)$. Mean VRT \&ART values $(0.146,0.137)$ decreased from the baseline values $(0.170,0.156)$ after RNB practice and was statistically significant $(\mathrm{p}<0.001)$.

Table 2: Comparison of VRT and ART before and after nasal breathing- Left and Right

\begin{tabular}{|c|c|c|c|c|c|c|c|}
\hline \multirow{2}{*}{$\begin{array}{c}\text { Nasal } \\
\text { breathing } \\
\text { side }\end{array}$} & \multirow{2}{*}{$\begin{array}{c}\text { Reaction } \\
\text { time } \\
(\mathrm{ms})\end{array}$} & \multicolumn{2}{|c|}{ Before } & \multicolumn{2}{|c|}{ After } & \multirow[t]{2}{*}{$\mathrm{t}$ test } & \multirow{2}{*}{$\begin{array}{c}p \\
\text { value }\end{array}$} \\
\hline & & Mean & SD & Mean & SD & & \\
\hline \multirow[t]{4}{*}{ Left } & $\begin{array}{l}\text { Green } \\
\text { light }\end{array}$ & .190 & .066 & .200 & .036 & -1.136 & 0.263 \\
\hline & Red light & .160 & .029 & .183 & .033 & -6.389 & $<0.001$ \\
\hline & Tone & .152 & .021 & .165 & .023 & -4.935 & $<0.001$ \\
\hline & Click & .158 & .033 & .177 & .037 & -5.877 & $<0.001$ \\
\hline \multirow[t]{4}{*}{ Right } & $\begin{array}{l}\text { Green } \\
\text { light }\end{array}$ & .177 & .031 & .154 & .029 & 7.290 & $<0.001$ \\
\hline & Red light & .163 & .026 & .140 & .02 & 7.807 & $<0.001$ \\
\hline & Tone & .153 & .019 & .134 & .025 & 5.204 & $<0.001$ \\
\hline & Click & .159 & .019 & .140 & .027 & 6.148 & $<0.001$ \\
\hline
\end{tabular}

In the LNB group there was no statistically significant increase in the VRT for green light, though there was an increase in the mean value (0.200) from the baseline (0.190).

Table 3: Comparison of VRT and ART before and after nasal breathing- in Males \& Females

\begin{tabular}{|l|l|l|r|r|r|r|r|r|}
\hline Test & Side & & \multicolumn{2}{|c|}{ Male } & \multicolumn{2}{c|}{ Female } & t test & p value \\
\cline { 4 - 8 } & & & Mean & SD & Mean & \multicolumn{1}{c|}{ SD } & & \\
\hline VRT & Left & $\begin{array}{l}\text { Green } \\
\text { light }\end{array}$ & .021 & .018 & .000 & .081 & 1.180 & 0.245 \\
\hline & & $\begin{array}{l}\text { Red } \\
\text { Light }\end{array}$ & .020 & .018 & .026 & .027 & -0.915 & 0.366 \\
\hline & Right & $\begin{array}{l}\text { Green } \\
\text { light }\end{array}$ & .018 & .019 & .028 & .021 & 1.456 & 0.154 \\
\hline ART & Left & $\begin{array}{l}\text { Red } \\
\text { Light }\end{array}$ & .020 & .023 & .031 & .017 & 1.687 & 0.1 \\
\hline
\end{tabular}




\begin{tabular}{|l|l|l|r|r|r|r|r|r|}
\hline & & Click & .015 & .022 & .022 & .018 & -1.123 & 0.269 \\
\hline & Right & Tone & .024 & .022 & .015 & .026 & -1.163 & 0.252 \\
\hline & & Click & .015 & .018 & .023 & .021 & 1.269 & 0.212 \\
\hline
\end{tabular}

$\mathrm{p}$ value was not significant. No gender difference in reaction time.

\section{Conclusion}

Audio Visual reaction time has an important role in everyday tasks. This simple and costeffective technique can be advised to students to overcome stress, for improvements in cognitive functions and to improve alertness and concentration. RNB has shown to stimulate sympathetic activity as evidenced by decrease in reaction time. LNB has shown to stimulate parasympathetic activity as evidenced by increase in reaction time. ART was faster than VRT. Reaction time for red light stimulus was faster when compared to green light. There was no gender difference in reaction time after breathing exercises.

Acknowledgement

We would like to acknowledge Dr. K .Jayashree, Assistant professor, Department of Community Medicine, Velammal Medical College for her help in statistical analysis and Ms. M. Dharani Devi, Technician, Department of Physiology, Velammal Medical College for her technical support.

\section{References}

1. Roni kahana-Zweig, Maya Geva-Sagiv, Aharon Weissbrod, Lavi Secundo, Nachum Soroker Noam Sobel. Measuring and characterizing the human nasal cycle. PLoS One.2016;11(10):e0162918.

2. Pal G.K, Velkumary.S, Madanmohan M. Effect of short term practice of breathing exercises on autonomic functions in normal human volunteers. Indian J Med Res. 2004;120(2):115-21.

3. Stancak A Jr, Kuna M. EEG changes during forced alternate nostril breathing. Int $\mathrm{J}$ Psychophysiol.1994;18(1)75-9.

4. Dane S, Caliskan E, Karasen M, Oztasan N. Effects of unilateral nostril breathing on blood pressure and heart rate in right handed healthy subjects. Int J neurosci .2002;112(1):97-102.

5. Backon J. Changes in blood glucose levels induced by differential forced nostril breathing, which affects brain hemisphericity and autonomic activity. Med Sci Res 1988;16:1197-9.

6. Chen JC, Brown B, Schmid KL. Effect of unilateral forced nostril breathing on tonic accommodation and intraocular pressure. Clin Auton Res.2004;14(6):396-400.

7. Bhavanani AB, Ramanathan M, Balaji R, Pushpa D. Differential effects of uninostril and alternate nostril pranayama on cardiovascular parameters and reaction time. Int J Yoga 2014;7(1):60-5.

8. Mahesh K Bhabhor, Kalpesh Vidja, Priti Bhanderi, Shital Dodhia, Rajesh Kathrotia,
Varsha Joshi. A comparative study of visual reaction time in table tennis players and healthy controls. Indian J Physiol Pharmacol 2013;57(4):439-42.

9. Shannahoff -Khalsa DS. The effects of unilateral forced nostril breathing on cognition. Int $\mathrm{J}$ Neurosci 1991;57:239-49.

10. Jella SA,Shannahoff -Khalsa DS. The effects of unilateral forced nostril breathing on cognitive performance. Int Jneuro 1993;73:61-8.

11. Telles S, Joshi M, Somvanshi P. Yoga breathing through a particular nostril is associated with contralateral event related potential changes. Int $\mathrm{J}$ Yoga 2012;5(2):102-7.

12. Gopal Krushna Pal, Ankit Agarwal, Nivedita Nanda. Slow yogic breathing through right and left nostril influences sympathovagal balance, heart rate variability, and cardiovascular risks in young adults. N Am J Med Sci 2014; 6 (3):14551.

13. Raghuraj P, Telles S. Immediate effect of specific nostril manipulating yoga breathing practices on autonomic and respiratory variables. Appl Psychophysiol Biofeedback. 2008;33(2):65-75.

14. Gallego J,Perruchet P. The effect of voluntary breathing on reaction time. J Psychosom Res 1993;37:63-70.

15. Heiser C, Baja J, Lenz F, Sommer JU, Hormann $\mathrm{K}$, Herr RM et al .Trigeminal induced arousals during human sleep. Sleep breath .2015;19(2):553-60.

16. Shannahoff -Khalsa DS, Sramek BB, Kennel MB, Jamieson SW. Haemodynamic observations on a yogic breathing technique claimed to help eliminate and prevent heart attacks: A Pilot study.J Altern Complement Med. 2004;10:75766.

17. Shenvi D, Balasubramanian P. A Comparative study of Visual and Auditory reaction time in males and females. Indian Journal of Physiol Pharmacol 1994;38(3):229-31.

18. Shelton J, Kumar G. Comparison between Auditory and Visual Simple reaction times. Neuroscience and Medicine.2010;1:30-2.

19. Ghuntla TP, Mehta HB, Gokhale PA, Shah CJ. A Comparison and importance of Auditory and Visual reaction time in Basketball players. Saudi J Sports Med2014;14:315-18.

20. Batra A,Vyas S,Jeph D. Colour difference on simple visual reaction time in young volunteers 2014;1(4):311-3.

21. Kalyanshetti SB. Effect of colour of object on simple Visual reaction time in normal subjects. JKIMSU 2014;3(1).

22. G.B Taware, M.V.Bhutkar. P. M. bhutkar, V.P Doijad and A.D surdi. Effect of Age on Audiovisual and Whole body reaction time. AJMS Al Ameen J Med (2012)5(1); 90-4.

23. Joseph CN, Porta C, Casucci G, Casiraghi N,Maffeis M, Rossi M, Bernardi L. Slow breathing improves arterial baroreflex sensitivity 
and decreases blood pressure in essential

hypertension.Hypertension.2005 Oct;46(4):714-8.

Indian Journal of Clinical Anatomy and Physiology, January-March, 2018;5(1);52-57 